\title{
The Ameliorative Potential of Saffron Against the Histological and Immunohistochemical Changes in Kidney of Albino Mice Due to Streptozotocin-Induced Diabetes Mellitus
}

\author{
Samir A. Nassar, Amal M. Hashim, Nahla H. Al-Shaer and Sahar M. Abd El-Salam \\ Zoology Department, Faculty of Science, Zagazig University, Egypt \\ Corresponding author: Samir A. Nassar; email: sanassar@ zu.edu.eg., Tel.+201003699657
}

\begin{abstract}
Background: multiple-organ failure is the chief inducer of death in diabetes mellitus and hyperglycaemiainduced oxidative stress is responsible for serious complications including nephropathy. Medicinal plants with antioxidant activity may ameliorate oxidative status and improve the histological and immunohistochemical lesions resulted in chronic hyperglycemia in diabetes.

Aim of the work: this study aimed to assess the beneficial effects of aqueous saffron extract (ASE) in streptozotocin (STZ)-induced diabetic mice by investigating the histopathological and immunohistochemical pattern in kidney tissues of different experimental groups.

Material and Methods: fasted mice were intraperitoneally (IP) injected by a single dose of a STZ (60 mg/kg body weight). After 24 hours, animals with fasting blood glucose over than $300 \mathrm{mg} / \mathrm{dl}$ were considered diabetic. The experimental groups were; control (1), saffron (2), diabetic (3) and diabetic + saffron (4). The treatment was started on the same day of STZ administration with oral gavage of ASE ( $80 \mathrm{mg} / \mathrm{kg}$ body weight) along with drinking water. At the end of the experimental period (45 days), fasting blood glucose was measured by blood strips using an Accu-Chick Performa device (Germany). Furthermore; histopathological and immunohistochemical studies were performed.
\end{abstract}

Results: Results showed that ASE significantly decreased blood glucose level and caspase-3 immunoexpression in treated diabetic mice as compared to untreated diabetic ones. Moreover, ASE improved the histopathological pattern to show a less injury.

Conclusion: administration of ASE showed significant ameliorative effects on the biochemical, histopathological and immunohistochemical parameters in kidney tissues of treated diabetic mice.

Keywords: saffron, STZ, diabetic nephropathy, histology, caspase-3, mice.

\section{INTRODUCTION}

Diabetes mellitus (DM) is a metabolic disorder with a high prevalence rate. Its prevalence is assumed to be around $6 \%$ up to $2025^{[1]}$. DM is characterized by hyperglycemia and is related to chronic disorders of carbohydrate, protein and lipid metabolism. If diabetes is not cured in time, it causes serious complications such as atherosclerosis, neuropathy, retinopathy and nephropathy ${ }^{[2]}$.

It has been confirmed that hyperglycemia supports oxidative stress with both enzymatic and nonenzymatic mechanisms ${ }^{[3]}$. Saffron is a widely used food additive; it is used in traditional medicine for the treatment of numerous diseases including depression, cognitive disorders, seizures and cancer [4].

Therefore, the aim of the present study was to investigate whether saffron supplementation could ameliorate histological and immunohistochemical changes in the kidney of albino mice due to streptozotocin-induced DM? It is an attempt to record a prophylactic role for saffron in hyperglycemia supporting the recent trend of alternative medicine. The onset which in turn may minimize the risk of diabetic complications that became direct causes for human death.

\section{MATERIAL AND METHODS Animals}

Forty adult male Albino mice weighing 25-30 g, 8 weeks old were used in this study. Animals were housed under standard laboratory conditions (five rats per cage, an ambient temperature of $25 \pm 2^{\circ} \mathrm{C}$, under a 12-h light/12-h dark cycle and open access to food and water). All experiments performed in accordance with the health guidelines for laboratory animals prepared by Zagazig University. After the acclimatization period, animals were equally categorized into 4 groups as follows: control (1), saffron (2), diabetes (3) and diabetes + saffron (4). Streptozotocin (STZ) (SigmaAldrich, USA) was dissolved in distilled water for rapid and effective induction of diabetes after 24 hours and injected intraperitoneally as a single dose $(60 \mathrm{mg} / \mathrm{kg} \mathrm{BW})$ to $\mathrm{G} 3$ and $\mathrm{G} 4{ }^{[5,6]}$. Blood samples were taken from the tail vein directly to the glucose strips for all studied groups.

Ethical approval:

This study was conducted in accordance with ethical procedures and policies approved by 
Animal Care and Use Committee of Faculty of science, Zagazig University.

Preparation of aqueous saffron extract (ASE)

The dried stigmas of Crocus sativus flower were obtained from Al-alawy Market, Jeddah, Saudi Arabia. Soak one gram of saffron in $100 \mathrm{ml}$ distilled water. Homogenize in the same distilled water After 2 hours, stir for 1 hour and filter. This aqueous extract was lyophilized and stored at $4{ }^{\circ} \mathrm{C}$ until further use ${ }^{[7]}$.

For histopathology and immunohistochemistry; $10 \%$ neutral formalin- fixed specimens of kidney were used, dehydrated in ascending series of ethanol, cleared in xylene and embedded in paraffin

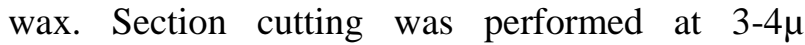
thickness, deparaffinized and processed for:

a- Hematoxylin and eosin (H \& E) staining ${ }^{[8]}$.

b- Masson's trichrome staining for collagen ${ }^{[9]}$.

c- To detect cytoplasmic apoptosis, immunohistochemical activity of caspase- 3 was tested. Avidin biotin complex immunoperoxidase technique was applied on paraffin sections. Blocking for endogenous peroxidase was done with methanolic $\mathrm{H}_{2} \mathrm{O}_{2}$ for 20 minutes. Biogenex Antigen Retrieval Citra solution in $90{ }^{\circ} \mathrm{C}$ water bath was used (30 minutes). Cool slides for 20 minutes then block by normal horse serum at 37 ${ }^{0} \mathrm{C}$ (5 minutes). Incubate sections for $18 \mathrm{hrs}$. at 4 ${ }^{0} \mathrm{C}$ with the antibody against caspase-3 (rabbit polyclonal antibody at dilution 1:200, Thermo Scientific, Ab-4). The immunohistochemical reaction was then developed and stained with diaminobenzidine chromogen solution "DAB" (Sigma). Counterstain with Mayr's hematoxylin and finally mount with DPX.

\section{Statistical analysis}

All data were analyzed using the SPSS 25.0 statistical package and expressed as mean \pm standard deviation. Statistical evaluation of significant difference between the means of groups was performed with one-way analysis of variance (ANOVA), followed by Tukey test and $\mathrm{p} \leq 0.05$ was regarded as significant.

\section{RESULTS}

\section{1-The glucose onset}

Testing of glucose status in our experiment revealed that injection of animals with STZ $(60 \mathrm{mg} / \mathrm{kg}$ b.w.) dissolved in distilled water resulted effectively in induction of diabetes within 24 hour. The glucose status in the present study exhibited some sorts of fluctuation in the different experimental groups as indicated in table land histogram 1. The blood glucose level of the control group was in the normal range during the time of the experiment. Animals of the saffron group exhibited a non-significant $(\mathrm{p} \leq$ 0.9300) difference in comparison with that of the control group after 45 days of administration it was nearly similar to the normal value. Glucose level was increased significantly $(\mathrm{p} \leq 0.0001)$ in the diabetic group after 45 days from STZ-injection (course of diabetes) as compared to the control group. The saffron aqueous extract was significantly $(\mathrm{p} \leq$ 0.0001 ) reduced the blood glucose levels of the diabetes + saffron group as compared to the diabetic group after 45 days from administration of saffron.

Table 1: glucose measurements for different groups of albino mice

\begin{tabular}{|l|l|l|l|l|}
\hline & Control & Saffron & Diabetic & $\begin{array}{l}\text { Diabetic } \\
+ \\
\text { Saffron }\end{array}$ \\
\cline { 2 - 5 } & c & s & D & D+S \\
\hline $\begin{array}{l}\text { Average } \\
\text { mean }\end{array}$ & 102.25 & 101.75 & 571.8 & 152 \\
\hline $\begin{array}{l}\text { Standard } \\
\text { deviation }\end{array}$ & 4.65 & 6.56 & 10.08 & 6.3 \\
\hline P Value & & 0.93 & 0.0001 & 0.0001 \\
\hline
\end{tabular}

Histogram 1: glucose measurements for different

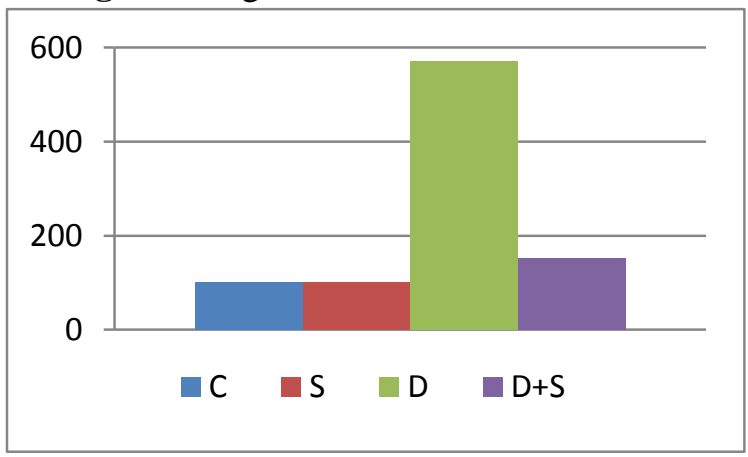

\section{The histopathological observations \\ $H$ and $E$ stained sections}

The light microscopic examination of $\mathrm{H}$ and $\mathrm{E}$ stained kidney tissue of the control and saffronadministered animals revealed a normal histological architecture (Figs. 1, 2). However, induction of diabetes mellitus in the experimental group resulted in several histopathological lesions including sclerotic and lobulated glomerulus with narrowing of the urinary space, necrotic proximal convoluted tubules and severely-damaged distal convoluted tubules in macula densa (Fig. 3). Administration of saffron in an oral dose of $80 \mathrm{mg} / \mathrm{kg}$ to the diabetic mice ameliorated the histological pattern of the renal tissue towards the normal status (Fig. 4). 

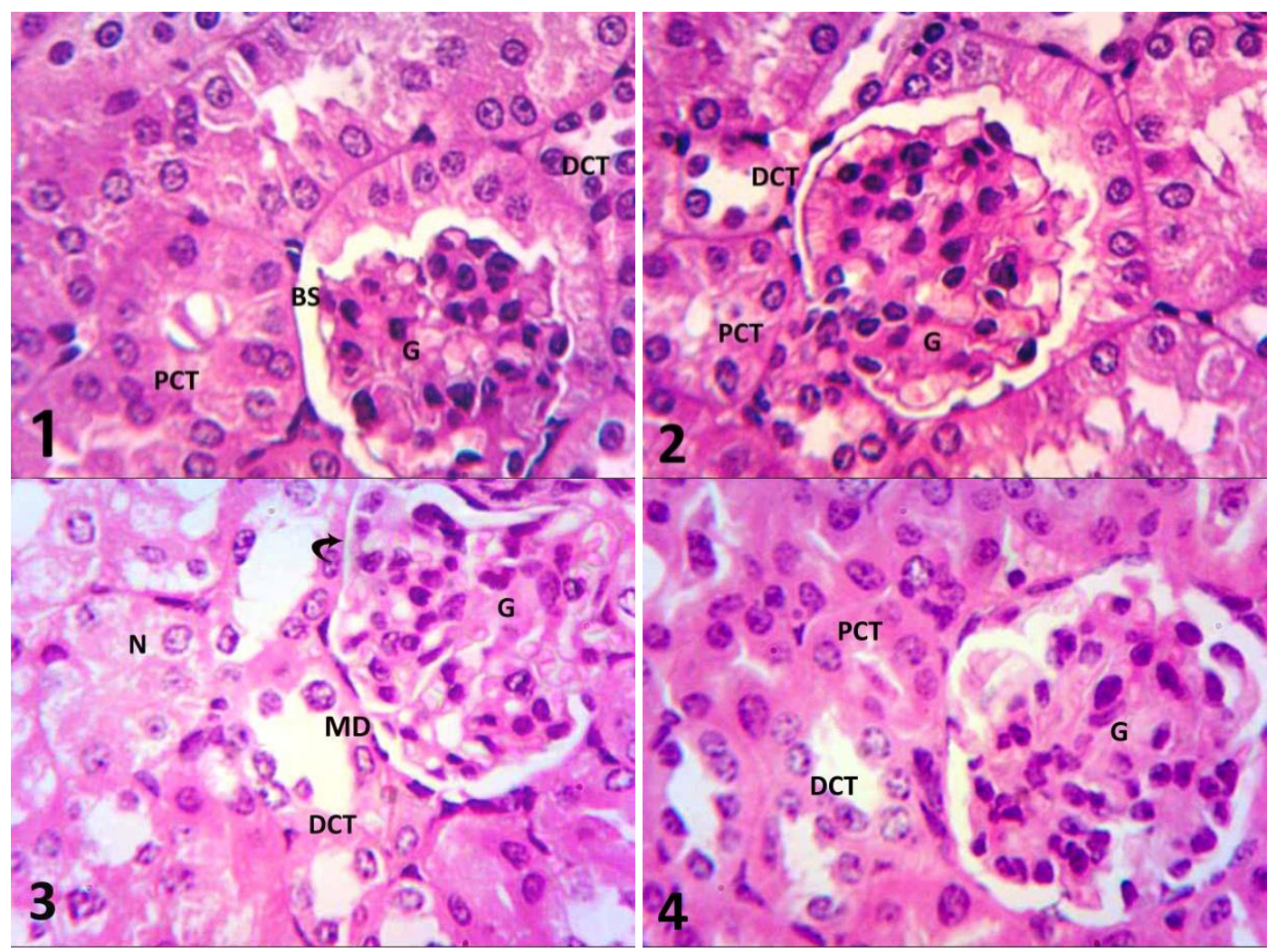

Fig. 1: section of kidney cortex of control mice (H\&E, x1000) showing a normal cortical elements; glomerular size (G), Bowman's space (BS), proximal and distal convoluted tubules (PCT \& DCT respectively).

Fig. 2: section of kidney cortex of saffron-administered mice (H\&E, x 1000) showing normal histological criteria for glomerulus $(\mathrm{G}), \mathrm{PCT}$ and DCT.

Fig. 3: section of kidney cortex of STZ-diabetic mice (H\&E, x1000) showing necrotic (N) proximal convoluted tubules, damaged distal convoluted tubules (DCT) in macula densa (MD) and lobulated and scelerotic glomerulus (G) with narrowed urinary space (curved arrow).

Fig. 4: section of kidney cortex of diabetic mice administered by saffron (H\&E, x1000) showing a nearly normal histological pattern of renal parenchyma; glomerulus $(\mathrm{G})$, PCT and DCT with a slight affection.

\section{Masson's trichrome stain}

The Masson's trichrome-stained kidney sections revealed the collagen status in the different experimental groups. A normal and minimal collagen distribution could be detected in the basement membranes of all renal tubules (peritubular), brush borders of the proximal convoluted tubules, periglomerular, mesangial matrix and in the renal interstitial tissue. (Fig. 5, table 2 and histogram 2).Elements of the renal tissue in mice-administered with saffron illustrated a collagen status nearly similar to that of the control animals (Fig.6). The image analysis recorded a significant decrease $(\mathrm{p} \leq 0.0478)$ as compared to that of the control value (Table 2 and histogram 2).Application of STZ to the experimental animals resulted in DM accompanied with extensive collagen deposition around the thickened congested blood vessel wall, peritubular and periglomerular (Figs.7, 8). This was confirmed by image analysis which recorded a highly significant increase $(\mathrm{p} \leq 0.0001)$ in collagen deposition in the elements of renal tissue as compared to that of the control animals (Table 2 and histogram 2).Treatment of the diabetic mice with saffron extract revealed minimal deposition of collagen in the periglomerular, peritubular, brush borders and mesangial matrix which recorded a significant decrease $(\mathrm{p} \leq 0.0001)$ in collagen deposition in the renal tissue towards the normal pattern as compared to the diabetic group (Fig. 9, Table 2 and histogram 2). 


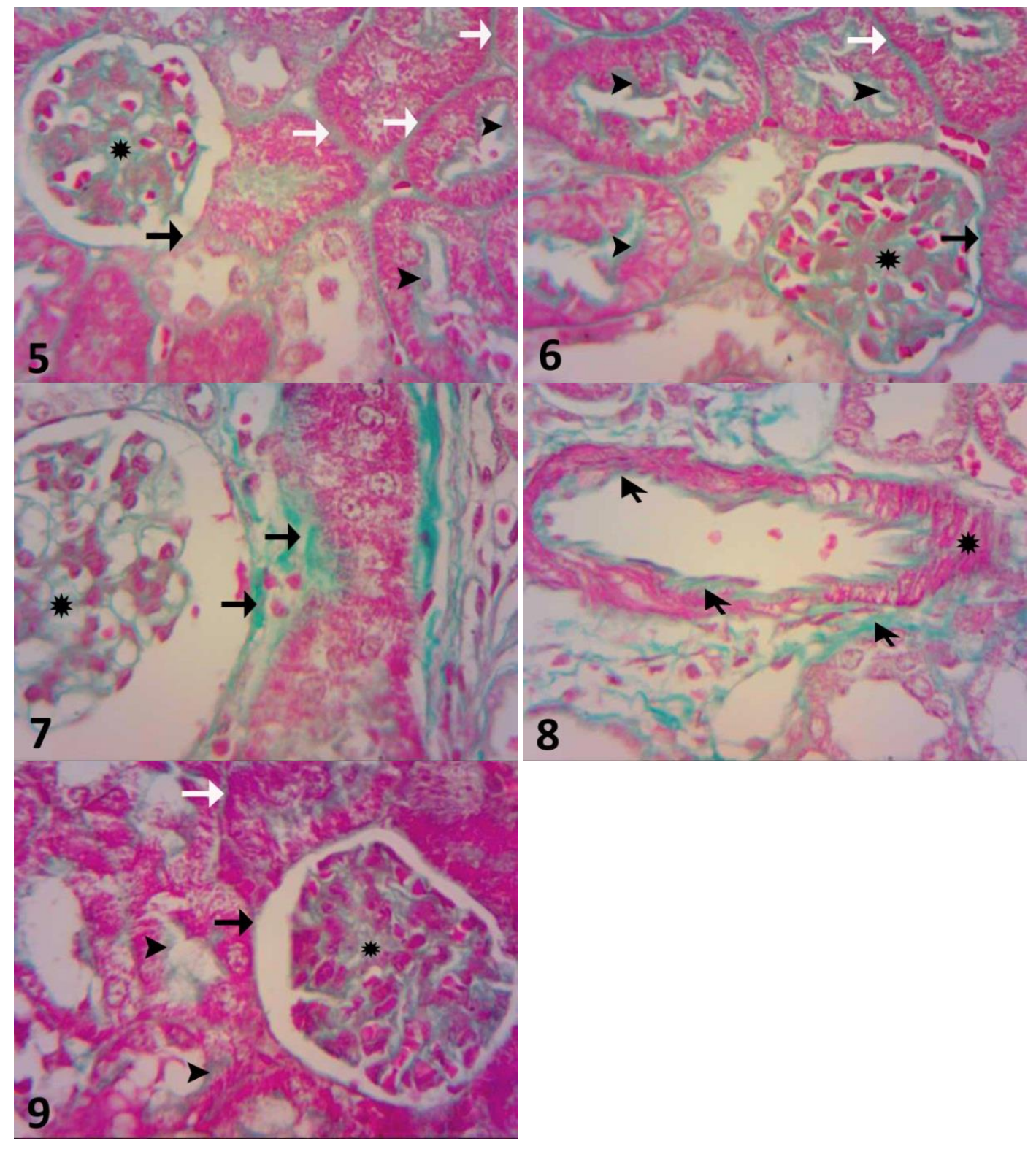

Fig. 5: section of kidney cortex of control mice stained with Masson's Trichrome (x1000) showing a normal collagen distribution could be detected in the peritubular (white arrows), brush borders (arrow heads) of the proximal convoluted tubules, periglomerular (black arrow) and mesangial matrix (asterisk).

Fig. 6: section of kidney cortex of saffron-administered mice stained with Masson's trichrome (x1000) showing nearly normal distribution of collagen in the renal tissue localized periglomerular (black arrow), peritubular (white arrow), in brush borders (arrow heads) of PCT and mesangial matrix (asterisk).

Fig. 7: section of kidney cortex of STZ-diabetic mice stained with Masson's trichrome (x1000) showing extensive collagen deposition in periglomerular (black arrows), peritubular and mesangial matrix (asterisk).

Fig. 8: section of kidney cortex of STZ- administered diabetic mice stained with Masson's trichrome (x1000) showing extensive collagen deposition (black arrows) around thickened congested blood vessel wall (asterisk).

Fig. 9: Section of kidney cortex of diabetic mice-administered by saffron stained with Masson's trichrome (x1000) revealed minimal collagen deposition in periglomerular (black arrow), peritubular (white arrow), brush borders (arrow heads) and mesangial matrix (asterisk) compared to diabetic group. 


\begin{tabular}{|l|l|l|l|l|}
\hline & $\begin{array}{l}\text { Control } \\
\text { c }\end{array}$ & $\begin{array}{l}\text { Saffron } \\
\text { S }\end{array}$ & $\begin{array}{l}\text { Diabetic } \\
\text { D }\end{array}$ & $\begin{array}{l}\text { Diabetic } \\
\text { + Saffron } \\
\text { D+S }\end{array}$ \\
\hline $\begin{array}{l}\text { Average } \\
\text { mean }\end{array}$ & 0.0693 & 0.0517 & 0.1885 & 0.1253 \\
\hline $\begin{array}{l}\text { Standard } \\
\text { deviation }\end{array}$ & 0.00216 & 0.00327 & 0.08446 & 0.00547 \\
\hline P Value & & 0.0478 & 0.0001 & 0.0001 \\
\hline
\end{tabular}

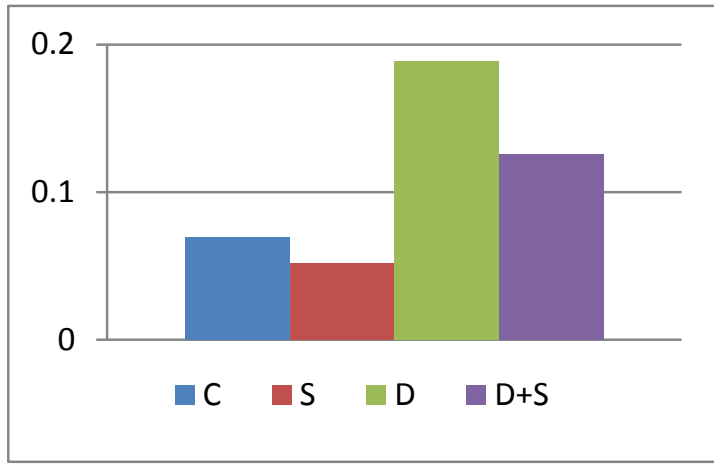

Table 2: mean optical density of collagen content in kidney of control and experimental groups Histogram 2: representation of collagen content in kidney of control and experimental groups

\section{3- Immunohistochemical observations \\ Caspase-3}

Application of caspase-3 immunostaining to the kidney sections of the experimental groups resulted in a negative reactivity for caspase- 3 in the glomeruli and renal tubules of both control and saffron groups (Figs 10, 11 , table 3 and histogram 3$)$. However, the activity of caspase- 3 was increased significantly $(p \leq 0.0001)$ in the damaged renal tissue of the diabetic animals as compared to that of controls (Fig. 12, table 3 and histogram 3). But, in the combined diabetic and saffron-administered mice, the caspase- 3 immunoreactivity was significantly decreased $(\mathrm{p} \leq 0.0001)$ as compared to all STZ-diabetic mice (Fig 13, table 3 and histogram 3 ).
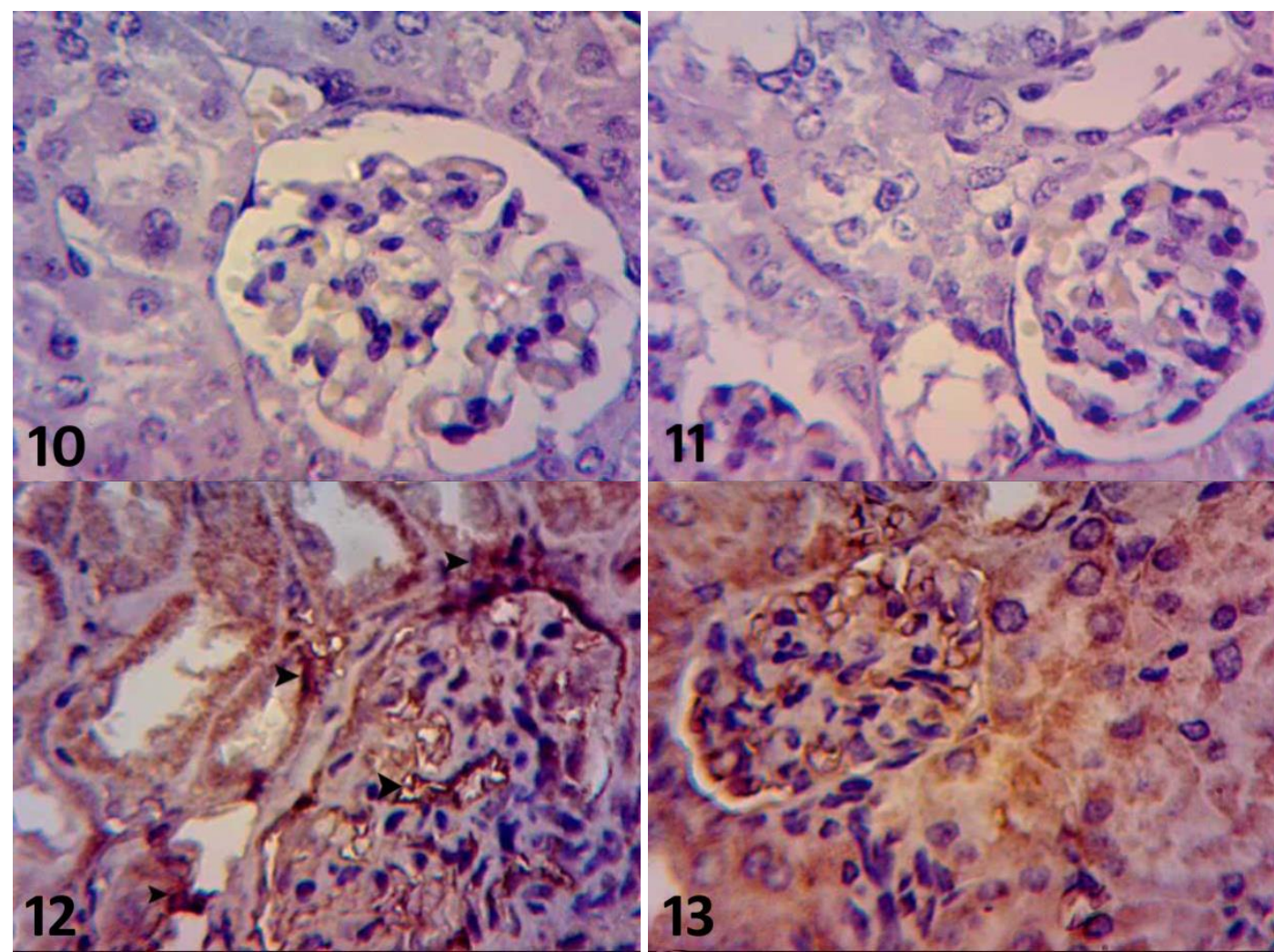

Figs. 10, 11: caspase-3 immunostainig (x1000) in the control and saffron-administered mice respectively showing a negative caspase staining in Malpighian corpuscle and renal tubules

Fig. 12: caspase-3 immunostaining (x1000) in STZ-diabetic mice showing increased immuoreactivity in renal elements glomerular area and tubulointerstitial (arrow heads)

Fig. 13: caspase-3 immunostaining (x1000) in STZ-diabetic mice treated with saffron exhibiting a decrease in caspase- 3 immunoreactivity as compared to the diabetic group 


\begin{tabular}{|l|l|l|l|l|}
\hline & $\begin{array}{l}\text { Control } \\
\text { c }\end{array}$ & $\begin{array}{l}\text { Saffron } \\
\text { S }\end{array}$ & $\begin{array}{l}\text { Diabetic } \\
\text { D }\end{array}$ & $\begin{array}{l}\text { Diabetic } \\
+ \\
\text { Saffron } \\
\text { D+S }\end{array}$ \\
\hline $\begin{array}{l}\text { Average } \\
\text { mean }\end{array}$ & 0.03914 & 0.03686 & 0.978143 & 0.793714 \\
\hline $\begin{array}{l}\text { Standard } \\
\text { deviation }\end{array}$ & 0.00279 & 0.00279 & 0.057429 & 0.011221 \\
\hline P Value & & 0.1519 & 0.0001 & 0.0001 \\
\hline
\end{tabular}

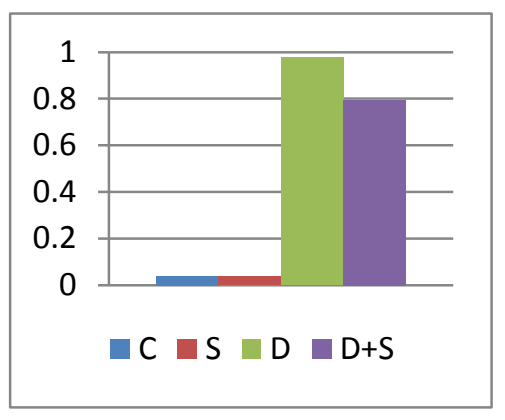

Table 3: mean optical density of caspase-3 immunoreactivity in the different experimental groups Histogram 3: concentration of caspase-3 immunoreactivity in the different experimental groups.

\section{DISCUSSION}

Testing of glucose status in our experiment revealed that the administration of animals with STZ dissolved in distilled water resulted effectively in the induction of diabetes within 24 hours with a significant increase in glucose status in the exposed animals which returned toward the normal state by treatment with (ASE) recording a hypoglycemic effect for saffron. These results are in agreement with those of other investigators who recorded a rapid induction of diabetes in albino mice after 24 hours of injecting STZ dissolved in distilled water ${ }^{[6]}$. This is also in line with a previous study which recorded a similar effect in alloxan-diabetic rats given saffron extract and crocin and safranal which are the active metabolites of saffron ${ }^{[10]}$. The hypoglycemic effect of saffron extract seems to be exerted by mechanisms including stimulation of glucose uptake by peripheral tissues ${ }^{[11]}$, inhibition of renal glucose reabsorption ${ }^{[12]}$ or correction of insulin resistance ${ }^{[13]}$, stimulation of $\beta$-cells of islets of Langerhans to release more insulin ${ }^{[14]}$ and regeneration of $\beta$-cells of islets of Langerhans ${ }^{[15]}$. The hypoglycemic effect of crocin was attributed to its free radicals scavenging properties, its ability to enhance host antioxidant defense system and its ability to inhibit inflammatory and fibrotic cascades activation and draw a mechanistic conclusion about its ability to suppress progression of diabetic nephropathy (DN) in a murine model of type-1 diabetes mellitus and DN therefore, they recording an ameliorative impact for saffron on $\mathrm{DN}^{[16]}$. Also, the present results concerning the glucose status support and extend previous results which recorded the ability of saffron to normalize the activity of kidney functional enzymes and its protective effect on diabetic renal disease [17]. Saffron extracts improved glycemic control by suppression of the pathophysiologic pathways involved in insulin resistance. They provide evidence suggesting that saffron is a safe and efficacious natural product that might serve an accessory role to routine anti-diabetic medications, and also as a dietary supplement to mitigate insulin resistance in pre-diabetic individuals ${ }^{[18]}$. Several advantages in reducing diabetes in mice using the treatment with the hydro alcoholic extract of saffron together with the consequences of diabetes, such as hypertriglyceridemia and hypercholesterolemia ${ }^{[19]}$.

Concerning the histopathological effects of diabetes recorded in the present study, application of STZ to the experimental animals resulted in several lesions including damaged, sclerotic and lobulated glomeruli and several necrotic foci in the renal tissue which may attribute to the oxidative stress of hyperglycemia. These results are in consistence with preceding studies which recorded glomerular degeneration, inflammation, karyolysis, karyorrhexis, necrosis, mesangial hypercellularity and expansion of glomeruli which associated with an increase in mesangial matrix and thickness of glomerular basement membrane in alloxan-diabetic rats ${ }^{[20]}$. Free oxygen radicals are highly toxic on all the cell components, especially in the cellular membrane. Increased free radical production exerts cytotoxic effects on the membrane phospholipid, resulting in the formation of toxic products such as malondialdehyde (MDA). The reactive oxygen species (ROS) take a role in the pathogenesis of many diseases including hypoxia, hypercholesterolemia, atherosclerosis, hypertension, ischemia-reperfusion damage, and heart defects ${ }^{[21]}$. It is thought that mesangial expansion reduces the capillary surface area available for filtration ${ }^{[22]}$. In mouse models of diabetic nephropathy, short-term consequences of diabetic nephropathy, including the development of the glomerular hyperfiltration, increased albuminuria and glomerular basement membrane (GBM) thickening, and mesangium expansion was demonstrated ${ }^{[23]}$. Renal histology 
showed corpuscular, tubular and interstitial changes. Changes in the corpuscles were related to the reduction of Bowman's space which could be due to the expansion of mesangial and/or endothelial cells of glomerulus. Expansion of mesangial region and basement membrane thickening could be reported in further studies, the role of the mesangium is to support and anchor the capillary loops to enable them to retain their structure and function ${ }^{[24]}$. The mesangial expansion is crucial was described as structural change leading to a loss of renal function in diabetes ${ }^{[25]}$. Changes in the parietal layer of Bowman's capsule characterized as metaplasia could be observed. Although the parietal layer has no role in the glomerular filtration, they assumed that beside glomerular expansion, the change of squamous epithelium into columnar could also contribute to the reduction of Bowman's space. It is known that changes in the structure and function of the glomerulus affect the tubules ${ }^{[26]}$.

Use of ASE in the present experiment minimized these histopathological changes in an obvious ameliorative effort. These observations support and extend previous results that recorded a marked reduction in histopathological changes in diabetic animals by crocin administration and the appearance of the kidney was nearly similar to the control group ${ }^{[27]}$. Also, safranal treatment to rats with DN reduced renal damage and consequently reduced the severity of nephropathy by decreasing the serum blood urea nitrogen and creatinine levels [28]. These results are in line with former ones performed a histopathological study recorded infiltration of lymphocytes in the interstitial spaces, glomerular hypertrophy and vacuolated cytoplasm of tubular epithelial cells in the untreated diabetic group. The injury in ASE treated diabetic group was less [17]. Also, crocin administration significantly ameliorated biochemical and histopathological parameters altered alongside DN progression. Crocin administration significantly reduced DNinduced increase in kidney/body weight ratio. In addition, it induced a significant normalization of parameters of renal functions including serum creatinine, BUN and protein in urine and enhanced creatinine clearance as well. It also antagonized DNinduced increase in serum LDH and catalase activity, suggesting anti-inflammatory properties ${ }^{[16]}$. In a recent study, it was demonstrated that saffron aqueous extract can protect the kidney and liver of diabetic rats against damage caused by hyperglycemia-induced inflammation, due to its anti- inflammatory potential ${ }^{[29]}$.

Concerning the collagen distribution in the renal tissue of experimental animals, in the current study, as affected by DM. Masson's trichrome stained sections revealed that the application of STZ resulted in extensive collagen deposition with a significant value around thickened congested blood vessel walls, peritubular and periglomerular localities. These results support and confirm observations reported that diabetic glomerulosclerosis is defined by an increase and accumulation of glomerular extra cellular matrix (ECM) that is mainly synthesized by mesangial cells that underwent an activation mediated by cytokines and growth factors from various cellular origins ${ }^{[30]}$. Provided evidence that the diabetic state stimulated synthesis of several ECM molecules in the kidneys of experimental diabetic animals ${ }^{[31]}$. Previous studies reported that basement membranes were thickened and ECM components such as laminin, fibronectin and type IV collagen were increased in short-term diabetics ${ }^{[32]}$. These data suggested that diabetic glomerulosclerosis is associated with an increase in the synthesis of GBM components. Moreover, disruption of the balance between production and degradation of ECM components may affect the thickening of basement membranes in DN ${ }^{[33]}$. Histological changes have been found recording mesangial expansion, thickening of the GBM, and glomerular sclerosis ${ }^{[34]}$. The mesangial expansion is directly induced by hyperglycemia, perhaps via increased matrix production or glycosylation of matrix proteins ${ }^{[35]}$. Thickening of the GBM in diabetic nephropathy occurs through upregulation of transforming growth factor- $\beta 1$ (TGF$\beta 1$ ) and connective tissue growth factor (CTGF) because they stimulate ECM accumulation and fibrotic effects ${ }^{[36]}$. The increase in collagen deposition in the present study could be ameliorated by the treatment of the diabetic animals with ASE and this is confirmed quantitatively by image analysis to record the protective potential of saffron. These findings are in agreement with other studies in which crocin recoded a significant histopathological improvement and reduced fibrotic tissue ratio confirmed with a reduction of percentage area of Masson's Trichrome positive tissues. It also preserved renal tubular integrity and decreased DNinduced decrease in the intra-glomerular space area as well ${ }^{[16]}$.

Since caspase- 3 is the key inducer of apoptosis in the living cell. Therefore, in the present study, it was taken as a marker to reflect the histophysiological state of the cell in the different experimental groups. In the current study, the kidney sections of diabetic animals exhibited a strong activity for caspase-3 with significant value. This increased immunoreactivity was minimized to 
decrease significantly approaching the normal status by the administration of saffron. Caspase- 3 is the most crucial enzyme in apoptosis and supplies a common pathway for apoptosis both induced by the death receptor-dependent on mitochondria. Caspase3 is associated with the pathogenesis of renal damage models related to apoptosis ${ }^{[37]}$. Studies used immunohistochemical and Western blot methods that find that caspase- 3 expression increased in the renal tissues of STZ diabetic mice compared to the control group. They also found that after the reninangiotensin system (RAS) blockage, there was a significant decrease in caspase-3 expression at renal tissues of diabetic mice ${ }^{[38]}$. Active caspase- 3 was located in the nuclei of these cells. In fact, caspase-3 is primarily in the cytoplasm and once activated is transported into the nucleus during apoptosis to gain access to its nuclear substrates, such as lamin B and nuclear pore complex proteins ${ }^{[39]}$. Also, our results are in agreement with those which demonstrated that increased expression of caspase-3, cyclooxygenase (COX) -1 and -2 , calcium-sensing receptor (CSR), and hypoxia-inducible factor- $1 \alpha(\mathrm{HIF}-1 \alpha)$ in the islet of Langerhans, liver, and kidney in STZ- induced DM in rats. These results supported the idea that cellular damages due to DM can occur in very early stages of the disease ${ }^{[40]}$.

\section{CONCLUSION}

Administration of ASE showed significant ameliorative effects on the biochemical, histopathological and immunohistochemical parameters in kidney tissue of treated diabetic mice which may suggest a prophylactic role in diabetic medication.

\section{REFERENCES}

1. Kim SH, Hyun SH and Choung SY (2006): Antidiabetic effect of cinnamon extract on blood glucose in db/db mice. J. Ethnopharmacol., 104: 119-123.

2. Marjani A (2010): Lipid peroxidation alteration in type 2 diabetic patients. Pak. J. Biol. Sci., 13: 723-730.

3. Coskun O, Ocakcı A, Bayraktaroglu T and Kanter M (2004): Exercise training prevents and protects streptozotocin-induced oxidative stress and $\beta$-cell damage in rat pancreas. Tohoku J. Exp. Med., 203: 145-154.

4. Bathaie SZ and Mousavi $Z$ (2010): New applications and mechanisms of action of saffron and its important ingredients. Crit. Re. Food Sci Nutr., 50: 761 - 786.

5. Al-Hariri M, T Gamal Eldin T, B Abu-Hozaifa B and Elnour A (2011): Glycemic control and anti-osteopathic effect of propolis in diabetic rats. Diabetes, Metaboli Syndrome and Obesity, 4: 377-384.

6. Nassar SA and Hashem AM (2017): Histological and immunohistochemical criteria of adrenal gland of albino mice due to streptozotocin-induced diabetes. Transylvanian Review, 25 (22): 5669-5678.

7. Premkumar K1, Abraham SK, Santhiya ST and Ramesh A (2003): Protective effects of saffron (Crocus sativus Linn) on genotoxins-induced oxidative stress in Swiss albino mice. Phytother. Res., 17 (6): 614-617.

8. Bancroft JD and Gamble M (2002): Theory and Practice of Histological Techniques. 6th ed. Philadelphia, PA : Churchill Livingstone/Elsevier, pp: 287-725.

9. Pearse A (1977): Histochemistry: Theoretical and Applied. $3^{\text {rd }}$ ed. Churchill Livingstone, London.

10. Kianbakht $S$ and Hajiaghaee $R$ (2011): Antihyperglycemic effects of saffron and its active constituents, crocin and safranal, in alloxan-induced diabetic rats. Journal of Medicinal Plants, 10 (39): 82- 89.

11. Yang YC, Hsu H, Hwang JH and Hong SJ (2003): Enhancement of glucose uptake in 3T3-L1 adipocytes by Toonasinensis leaf extract. J. Ed. Sci., 19: 327-333.

12. Maghrani M, Michel JB and Eddouks M (2005): Hypoglycemic activity of Retama raetam in rats. Phytote. Res., 19: 125-128.

13. Hu X, Sato J, Oshida Y, Xu M, Bajotto G and Sato $Y$ (2003): Effect of Gosha-jinki-gan (Chinese herbal medicine Niu-Che-Sen-Oi-Wan) on insulin resistance in streptozotocin-induced diabetic rats. Diabetes Res. Clin. Pract., 59: 103-111.

14. Xi L, Qian Z, Xu G, Zhou C and Sun S (2007): Crocetin attenuates palmitate-induced insulin insensitivity and disordered tumor necrosis factor- $\alpha$ and adiponectin expression in rat adipocytes. Br. J. Pharmacol., 151: 610 617.

15. Elgazar AF, Rezq AA and Bukhari HM (2013): Antihyperglycemic effect of saffron extract in alloxan-induced diabetic rats. European Journal of Biological Sciences, 5 (1): $14-22$.

16. Abou-Hany HO, Atef H, Said E, Elkashef A and Salem HA (2018): Crocin mediated amelioration of oxidative burden and inflammatory cascade suppresses diabetic nephropathy progression in diabetic rats. ChemicoBiological Interactions, 284: 90-100.

17. Ashrafi M, Nazifi S, Namazi F, Kazemipour N, Karimi B, Goudarzi T and Talebanzadeh S (2017): Renal protective effect of saffron aqueous extract in streptozotocin induced diabetic rats. International Journal of Medical Research Health Sciences, 6 (9): 151-161.

18. Yaribeygi H, Zare V, Butler AE, Barreto GE and Sahebkar A (2018): Antidiabetic potential of saffron and its active constituents. Wiley J. Cell Physiol., 234: 86108617.

19. Faridi S, Delirezh $N$ and Froushani S (2019): Beneficial effects of hydroalcoholic extract of saffron in alleviating experimental autoimmune diabetes in C57bl/6 mice. Iran J. Allergy Asthma Immunol., 18 (1): 38-47.

20. Shaffie NM, Morsy FA, Ali AG and Sharaf HA (2010): Effect of craway, coriander and fennal on the structure of kidney and islets of langerhan in alloxan-induced diabetic rats: histological and histochemical study. Researcher, 2(7): 27-40. 
21. Wilcox CS and Gutterman D (2005): Focus on oxidative stress in the cardiovascular and renal systems. Am. J. Physiol. Heart Circ., 288: 3-6.

22. Wolf G, Chen SD and Ziyadeh FN (2005): From the periphery of the glomerular capillary wall toward the center of disease - Podocyte injury comes of age in diabetic nephropathy. Diabetes, 54: 1626-1634.

23. Breyer MD, Böttinger E, Brosius FC, Coffman TM, Harris RC, Heilig CW and Sharma K (2005): AMDCC, mouse models of diabetic nephropathy. Journal of American Society of Nephrology, 16: 27-45.

24. Teoh SL, Abd Latiff A and Das S (2010): Histological changes in the kidneys of experimental diabetic rats fed with Momordica Charantia (bitter gourd) extract. Romanian J. of Morphology and Embryology, 51(1): 9195.

25. Fioretto $P$ and Mauer $M$ (2007): Histopathology of diabetic nephropathy. Semin. Nephrol., 27: 195-207.

26. Orsolic N, Sirovina D, Koncic MZ, Lackovic G and Gregorovic G (2012): Effect of Croatian propolis on diabetic nephropathy and liver toxicity in mice. BMC Complementary and Alternative Medicine, 12 (117): 115.

27. Altinoz E, Oner Z, Elbe H, Cigremis $Y$ and Turkoz $Y$ (2015): Protective effects of saffron (its active constituent, crocin) on nephropathy in streptozotocin-induced diabetic rats. Human and Experimental Toxicology, 34 (2): 127 134.

28. Hazman O and Bozkurt MF (2015): Anti-inflammatory and antioxidative activities of safranal in the reduction of renal dysfunction and damage that occur in diabetic nephropathy. Springer Science (New York), 38: 15371545.

29. Ashrafi M, Afsar Z, Erjaee $H$ and Nazifi $S$ (2018): The effects of saffron (Crocus sativus) aqueous extract on TNF- $\alpha$ levels in liver, kidney, and lens tissues of diabetic rats. Turk. J. Endocrinol. Metab., 22: 217-224.

30. Sassy-Prigent C, Heudes D, Mandet C, Belair MF, Michel O, Perdereau B, Bariety $\mathbf{J}$ and Bruneval $\mathbf{P}$ (2000): Early glomerular macrophage recruitment in streptozotocin-induced diabetic rats. Diabetes, 49: 466475 .
31. Kanter M (2009): Protective effects of thymoquinone on streptozotocin-induced diabetic nephropathy. J. Mo. Histol., 40: 107-115.

32. Park IS, Kiyomoto H, Abboud SL and Abboud HE (1997): Expression of transforming growth factor-beta and type IV collagen in early streptozotocin-induced diabetes. Diabetes, 46: 473-480.

33. Funabiki K, Makito Y, Yamamoto M, Shike T, Fukui M, Sumiyoshi Y and Tomino Y (1998): Dissociated expression of collagen type IV subchains in diabetic kidneys of KKAy mice. Nephron, 80: 208-213.

34. Omran (2014): Effects of thymoquinone on STZ-induced diabetic nephropathy: an immunohistochemical study. Ultrastructural Pathology, 38 (1): 26-33.

35. Makino H, Miyamoto Y, Sawai K, Mori K, Mukoyama M, Najao K, Yoshimasa Y and Suga S (2006): Altered gene expression related to glomerulogenesis and podocyte structure in early diabetic nephropathy of $\mathrm{db} / \mathrm{db}$ mice and its restoration by pioglitazone. Diabetes, 55: 2747-2756.

36. Zhou G, Li C and Cai L (2004): Advanced glycation end-products induce connective tissue growth factormediated renal fibrosis predominantly through transforming growth factor beta-independent pathway. Am. J. Pathol., 165: 2033-2043.

37. Bamri-Ezzine S, Ao ZJ, Londoño I, Gingras D and Bendayan M (2003): Apoptosis of tubular epithelial cells in glycogen nephrosis during diabetes. Lab. Investig., 83: 1069-1080.

38. Liu F, Brezniceanu ML, Wei CC, Chénier I, Sachetelli S, Zhang SL, Filep JG, Ingelfinger JR and Chan JS (2008): Overexpression of angiotensinogen increases tubular apoptosis in diabetes. J. Am. Soc. Nephrol., 19: 269-280.

39. Buendia B, Santa-Maria A and Courvalin JC (1999): Caspase-dependent proteolysis of integral and peripheral proteins of nuclear membranes and nuclear pore complex proteins during apoptosis. J. Cell Sci., 112: 1743-1753.

40. Haligur M, Topsaka S and Ozmen O (2012): Early degenerative effects of diabetes mellitus on pancreas, liver and kidney in rats: an immunohistochemical study. Experimental Diabetes Research, 2012: 1-10. 